\title{
Understanding the Economic Contribution of Tourism in Malta: A Literature Review
}

\author{
lan P. Cassar \\ Economics Department of the University of Malta \\ Corresponding Author Email: ian.p.cassar@um.edu.mt \\ Kevin Vella \\ Economic Policy Department, Ministry for Finance, Malta \\ Sean Buttigieg \\ Economic Policy Department, Ministry for Finance, Malta
}

Doi:10.5901/mjss.2016.v7n6p49

\begin{abstract}
The paper presents a critical assessment of the key studies which present empirical estimates for the contribution of the tourism sector to the Maltese economy. The observed discrepancies in the estimates derived from these studies has in part led to a situation in which there is an effective widespread divergence relating to the specific economic contribution of tourism in Malta. The paper evaluates the estimates derived by these key studies in the context of both the strengths and weaknesses of their respective modelling frameworks, which range from the construction of tourism satellite accounts, to input-output models and computable general equilibrium modelling, as well as an evaluation of the overall quality of the data utilized. The paper therefore attempts to identify and clarify the main causes behind the observed variations in the resulting estimates and through a systematic comparative assessment also aid in the providing a further understanding of the potential economic contribution of tourism to the Maltese economy. On the basis of this assessment it is suggested that the contribution of tourism to the Maltese economy should account for approximately $5.7 \%$ of total gross value added when taking account solely direct effects, $12 \%$ once indirect effects are included and roughly $17 \%$ accounting also for the induced effects. Furthermore, on the basis of this assessment the paper highlights the need for further research in this area given the significance of the tourism sector to the small island economy of Malta.
\end{abstract}

Keywords: tourism contribution, Malta, input-output analysis, multiplier

\section{Introduction}

In 2015, tourists visiting the Maltese Islands amounted to a record 1.79 million, staying an average close to eight nights and spending a total of approximately €1.64 billion, or approximately $18.7 \%$ of Gross Domestic Product (GDP). In addition, around half a million tourists visited Malta via luxurious cruise liners which berth in the majestic Grand Harbour. Whilst the typical tourist is British, Malta has become a popular destination with Italian, German, French and Spanish tourists which together with the British accounted for $63.2 \%$ of all tourist visitors to Malta in 2015 . The industry directly generates around 10,000 full-time jobs in accommodation and food services alone ${ }^{1}$.

Whilst tourism has long been regarded as one of the key pillars of the Maltese economy, there is widespread disagreement about the exact economic contribution of tourism. Some estimate its contribution at almost $30 \%$ of the economy (Blake et al., 2003; WTTC, 2015). Recent reports, namely the European Commission's 'Country Report March 2014' and the OECD 'Tourism Trends and Policies Malta 2014' also refer to a contribution of tourism in Malta of approximately $30 \%$ of GDP. However, the results from a number of empirical studies, which will be discussed in the paper, indicate that this estimate may, to a large extent, be overstated.

In an attempt to construct the first Tourism Satellite Account (TSA) for the Maltese economy ${ }^{2}$, Sacco (2016) estimates a more conservative contribution of Malta's tourism industry at $5.7 \%$ of the total Gross Value Added (GVA) (or $6.1 \%$ of GDP). Furthermore, an assessment of the results obtained from studies which apply input-output modelling

${ }_{1}^{1}$ For the latest main tourism indicators refer to Appendix Table 1.

${ }^{2}$ The Tourism Satellite Account for the Maltese economy was constructed by Sacco (2016) for the reference year of 2010. 
techniques, namely, Blake et al. (2003), Cassar (2015) and the Maltese National Statistics Office (NSO, 2016) also indicate a more conservative contribution to the economy when compared to those put forward by the WTTC 3 .

\section{Scope and Methodology}

The underlying aim of this paper is to identify and clarify the main causes behind the observed variation of the contribution (or impact) of the tourism sector to the Maltese economy which may be observed amongst various studies. The methodology employed is primarily a literature review of the key studies which have been undertaken with the aim to empirically assess the economic impact of tourism in Malta. The paper will identify estimates of the tourism contribution from various sources and compare and contrast the different methodologies employed thus providing a critique of the analysis and a comparison of results. The selection criteria for the studies assessed in this paper was that of selecting those studies which would allow for an appropriate identification and analysis of the contribution to the Maltese economy of the tourism sector which takes account of the direct, indirect and induced effects. The analysis undertaken in this literature review is disaggregated into three main sections, each focusing on the most relevant studies which have been undertaken aimed at capturing or measuring one or all of these three effects, either individually or simultaneously, namely, the use of a TSA, the application of input-output models and the application of computable general equilibrium models. It should be noted that each of these methods varies considerably in terms of modelling complexity and the robustness of the results obtained from their application rests significantly on the overall quality of underlying data utilized. An overall discussion which incorporates the analysis undertaken throughout all three sections is presented in the conclusion.

\section{Contribution of the Tourism Sector Based on Tourism Satellite Accounts}

Within the context of national accounting, an industry is typically measured from the output side by calculating the value added (namely total turnover less intermediate cost) of each producer within that given industry. However, unlike traditional sectors such as agriculture and transport, there is no industry classification under the European Statistical Classification of Economic Activities (NACE) Rev.2. that is specific to the tourism industry (or sector). This issue stems predominately from the underlying nature of tourism activities, in that the sector's supply and demand engages a wide range of activities to and from multiple sectors (Hara, 2008). It should be noted that it is nonetheless possible to assess those industries which are mostly associated with tourism activities which do have a NACE classification, such as the "accommodation" industry and the "food service" industry. Together, these two industries amounted to 5.2\% of GVA in 2015. But not all of the value added generated by these industries is attributable to tourist demand. Likewise, the value added generated by museums and heritage sites is classified under the recreation and culture sector. But most of the visitors are tourists and thus can be classified under the tourism industry.

In order to appropriately measure the full extent of tourism activities from both the demand and the supply side, national statistics offices generally compile what are known as Tourism Satellite accounts (TSAs). TSAs analyse in detail all aspects of the demand for goods and services associated with the activity of visitors; to observe the operational interface with the supply of such goods and services within the economy; and describe how this supply interacts with other economic activities (TSA: RMF 2008). TSAs are not a modelling but an accounting tool that records annual activities of tourism as an industry (Hara, 2012). The TSA is an extension to the system of national accounts which enables an understanding of the size and role of economic activity related to tourism which may not be clearly captured by national accounts.

The TSA is made up of a unique set of inter-related tables that show the size and the distribution of the different forms of tourism consumption in a country and contributions to GDP, national income, employment, and other macroeconomic measures of a national economy. Outputs derived from the TSA can be directly compared to main macroeconomic aggregates produced by the system of national accounting for other industries within the economy (Hara, 2008).

A study by Sacco (2016) presents the first attempt to construct a set of TSA tables for the Maltese economy in which estimates for the direct contribution of the tourism sector to the total GVA generated in the Maltese economy are presented based on two methodologies. Sacco (2016) estimates that Malta's tourism industry directly generated an amount of GVA equal to 330.4 million Euro during 2010, which equates to approximately 5.7\% of total GVA generated.

${ }^{3}$ WTTC is a forum for travel and tourism industry made up from the global business community and works with governments to raise awareness about the importance of tourism. 
This estimate is generated by subtracting the proportional value of intermediate consumption from the tourism share of output for each tourism related sector. Given that this method is however subject to criticism (OECD, 2000), the net ratio approach, which is an OECD recommended methodology (OECD, 2000), is also applied in order to calculate total direct gross value added (TDGVA). One of the key characteristics of this approach is the application of specific intermediate consumption to output ratios, relating to the main characteristic industry of each product, in such a manner that each product is now allocated a quantity of intermediate inputs which are characteristic to that of the associated industry, rather than the specific product type. The TDGVA derived by Sacco (2016), based on the net ratio approach, estimates that Malta's tourism industry directly generated an amount of GVA equal to 330.1 million Euro during 2010. This implies that both methods estimate an approximately consistent level of direct contribution to total GVA generated by the tourism sector, which in 2010 amounted to $5.7 \%$. It is important to note that tourism satellite accounts assess the direct contribution of the tourism sector but do not include the indirect effects on other industries and induced effects from consumption generated through the generation of salaries and wages.

\section{The Input-Output Modelling Approach to Measuring Tourism's Contribution}

To capture indirect and induced effects, an input-output framework is required. An input-output model is a quantitative economic technique that represents the interdependencies between different sectors of an economy. Input-output tables track the output generated by an industry as the intermediate input in the production process of another industry or the final purchase by the various consumers (Miller and Blair, 2009). Nevertheless, it is important to note that traditional input-output framework assumes fixed prices and the use of capital and labour in fixed proportions. In reality, an increase in tourist demand may not necessarily increase output of other industries in the presence of supply constraints in those industries which would compel them to raise prices rather than meet the excess demand through higher production. Thus, the assumptions underlying input-output models may not always hold, therefore leading to possible overestimations of the contribution of a given sector. In addition, the input-output framework assumes that a change to final demand, and thus also tourism expenditure, will not lead to any changes in the technology of production as well as no changes in the proportion of capital and labour used within the production process. Although one acknowledges the empirical usefulness of input-output methodologies, this framework's underlying modelling assumptions imply that empirical results need to be evaluated with caution, particularly in the presence of significant changes in the composition of tourism expenditure over time and the possibility of potentially overestimating the indirect contribution of tourism.

Through input-output methodology it is also possible to capture the fact that to generate its output, the tourism industry employs workers in return for wages and salaries, which income they spend on goods and services. Thus, the initial tourist expenditure also generates these 'induced effects'. In this respect, another limitation is that the standard input-output framework ignores the impact on savings when indeed an increase in tourism related income need not be entirely consumed and could even be associated with an increase in the marginal savings rate and hence a lower induced effect than the one portrayed by the input-output framework. It should be noted that although three studies which are to be discussed in this section compute various types of multipliers, such as the output multipliers ${ }^{4}$ and employment multipliers ${ }^{5}$, it was decided that emphasis should be placed primarily on value added multipliers. These are the multipliers which adhere closest to the statistical concept of GDP and thus lead to a better understanding of the contribution of tourism to the Maltese economy. Despite the limitations just highlighted, the use of input-output models remains important in understanding the linkages between tourism and the rest of the economy and in comparing the multipliers of the different industries with those of tourism.

\subsection{Industry Linkages and Multipliers in Tourism derived from an IOT for 2001}

Blake et al. (2003) in their Stage 2 Report calibrated a 10 industry Input-Output table for Malta using data for 2001. The main tourism sectors examined in the model were accommodation, restaurants, car hire and the national airline. A total spending of $€ 750$ million (Lm322 million or 19\% of 2001 GNP) left less than half of it (i.e. 9\% of GNP) in the economy

\footnotetext{
${ }^{4} \mathrm{~A}$ type I output multiplier for a given sector $j$ may be defined as the total value of production in all sectors of the economy that is necessary in order to satisfy a 1 euro worth of final demand for sector j's output (Miller and Blair, 2009). This multiplier is primarily utilized an indicator of the degree of structural independence between the industries in the economy.

5The employment-output multipliers derived in Cassar (2015) and Blake et. al. (2003) are also referred to as physical employment-output multipliers (Miller and Blair, 2009). They assess the effects, in terms of monetary income, that changes in the final demand for a sector have terms of the physical amount of jobs created.
} 
when leakages such as imports are excluded, representing the direct contribution. Nevertheless, this expenditure generated further 'indirect' expenditure in other industries. If one includes these indirect effects, the tourism industry may be said to have contributed to $€ 465$ million (or 12\% of GNP) in the Maltese economy in direct and indirect effects. Blake et al. (2003) estimate the induced effects at €184 million or $4.8 \%$ of GNP. Should these be added, in total, it would bring the total contribution of tourism to almost $17 \%$ of GNP. The main multiplier results obtained from the study by Blake et al. (2003) are illustrated in the Table 1.

Table 1: Stage 2 Report (2003) - Input-Output Model

\begin{tabular}{|c|c|c|c|c|}
\hline Malta (2001) & \multicolumn{2}{|c|}{ Direct Direct + Indirect } & Direct + Indirect + Induced & $\begin{array}{l}\text { Direct + Indirect + Induced + Government } \\
\text { Interacting }\end{array}$ \\
\hline \multicolumn{5}{|c|}{ The Economic Impact of Tourism } \\
\hline GNP (million LM) & 155 & 200 & 279 & 480 \\
\hline GNP (\% share) & 9.5 & 12.3 & 17.1 & 29.5 \\
\hline \multicolumn{5}{|l|}{ Multiplier } \\
\hline GNP (million LM) & 0.49 & 0.63 & 0.87 & 1.5 \\
\hline
\end{tabular}

Source: Blake et al. (2003)

The tourism value added multiplier derived in Blake (2003) is less than unity (0.63) when taking accounting of both the direct and indirect effects. Direct impacts reflect the value added generated domestically by the tourism sector. Indirect impacts represent the value added remaining after several rounds of spending by industries linked with tourism. A multiplier which includes both the direct and indirect effects is referred to as a Type I multiplier. When one includes the change in household consumption generated by changes in the wages and salaries earned as a result of the direct and indirect effects of economic activity taking place in the tourism sectors (i.e. the induced effects), the gross value added multiplier for tourism is still below unity. This is called the Type II value added multiplier and in the case of tourism is estimated at 0.87 (Blake et al., 2003). Blake et al. (2003) also chose to include a government interacting effect which raises the tourism contribution to almost $30 \%$, however, it should be noted that underpinning the government interacting multipliers are some very rigid assumptions which exclude significant behavioural effects and which most likely result in a substantial overstatement of the true economic contribution of tourism? ${ }^{7}$.

\subsection{Industry Linkages and Multipliers in Tourism derived from a SIOT for 2008}

The study by Cassar (2015) is based on a Symmetric Input-Output Table (SIOT) for 2008 which follows ESA95, which compared to Blake et al., (2003) provides a more updated assessment of the impact of tourism-related industries. Cassar (2015) constructed an industry-by-industry SIOT for Malta for the year 2008, based on the fixed production sales structure assumption. In his study, Cassar (2015) was able to derive industry specific multipliers based on the inputoutput methodology framework at a highly disaggregated 59 industry level. The industries that we consider to be an "integral" part of tourism are the land transport, water transport, air transport, and accommodation and food services activities. It is important to note that there may be elements within these industries that do not specifically pertain to the tourism industry. Furthermore, elements of the tourism industry may be included in other sectors of the economy, but are not included as part of this analysis.

The value added multipliers generated by Cassar (2015) for the four sectors identified as representative of the tourism sector in Malta are reproduced in Table 2 and are utilized to compute a weighted average tourism multiplier ${ }^{8}$ in order to allow a comparison with the estimate presented within Blake et al. (2003). Notwithstanding the differing reference years of the datasets utilized, and to an extent the methodologies applied, both multiplier estimates seem relatively consistent.

${ }^{6}$ The Euro replaced the Maltese lira (MTL) as the official currency of Malta on 1st January 2008 at the irrevocable fixed exchange rate of 0.4293 MTL per 1 Euro.

${ }^{7}$ A summary of the full set of multipliers relating to the tourism related sectors derived by Blake et al. (2003b), including the employment multipliers, may be found in Appendix Table 2.

${ }^{8}$ The weighted average tourism multiplier is derived by multiplying each individual industry value-added multiplier to the sectors' proportional percentage share of GVA or weighting) and aggregating across the respective four sectors. 
Table 2: A Comparison of Tourism GVA Multipliers based on Cassar (2015)

\begin{tabular}{|c|c|c|c|c|}
\hline & GVA in 2008 & Weight (\%) & GVA Type I Multipliers & GVA Type II Multipliers \\
\hline Land Transport and transport via pipelines & 55,455 & 14.7 & 0.69 & 0.88 \\
\hline Water Transport & 18,714 & 4.9 & 0.52 & 0.71 \\
\hline Air Transport & 47,589 & 12.6 & 0.46 & 0.74 \\
\hline Accommodation and Food Services & 256,813 & 67.8 & 0.65 & 0.93 \\
\hline Total & 378,571 & 100 & & \\
\hline 2008 Weighted Average Tourism Multipli & & & 0.63 & 0.89 \\
\hline
\end{tabular}

The analysis by Cassar $(2015)^{9}$ allows us to compare the multiplier effect of tourism-related industries with other industries present in the Maltese economy and thus provides a ranking. At 0.63 , the weighted average of the tourismbased industries suggests slightly below average value added multiplier (i.e. average is equal to 0.64). Type I value added multiplier for land transport is ranked amongst the median of the various industry output multipliers, with a value of 0.69. The same level of ranking can be attributed to the accommodation and food services activities, with a Type I multiplier value of 0.65 , made up of a high direct effect of 0.40 , and a slightly lower indirect effect of 0.25 . On the other hand, despite a relatively high output multiplier, both water transport and air transport exhibited rather low value added multipliers. The latter two sectors had amongst the lowest ranked direct effects, but at the same time had amongst the highest ranked indirect effects reflecting the significant linkages with the rest of the economy.

When one also considers the induced effects it is interesting to note that the industry ranking by strength of Type II value added multipliers improves significantly in the case of accommodation and food services and in air transport, reflecting their labour intensity of production. Chart 1 illustrates the value added multipliers of the tourism related industries.

Chart 1: 2008 Value Added Multipliers*

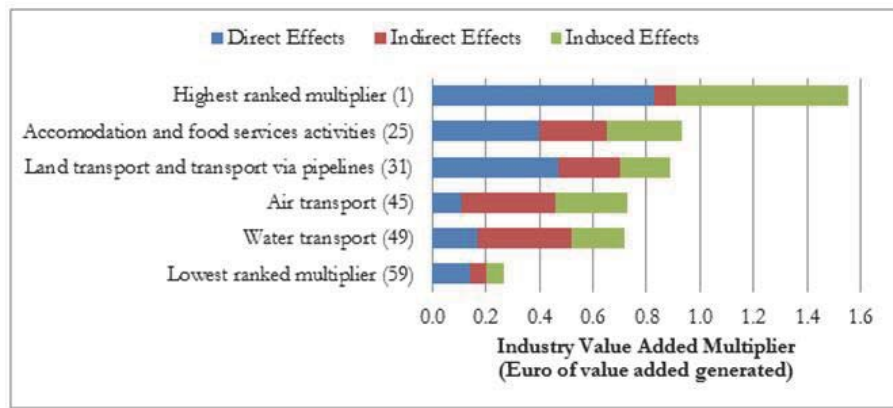

* The numbers in the brackets represent the rankings of the Type II multiplier.

Source: Cassar (2015)

\subsection{Industry Linkages and Multipliers in Tourism derived from a SIOT for 2010}

In May 2016 the National Statistics Office (NSO) published "Supply, Use and Input-Output Tables 2010" which presented the first official SIOT for Malta, since the SIOT for 1996 which was published in the National Statistics 1998 by the National Statistics Office of Malta. This publication also presented a set of Type I output and value-added multiplier derived utilizing the SIOT for 2010. It should be noted that in contrast to the SIOT utilized by Cassar (2015), which was based on ESA95 methodology, the SIOT for 2010 compiled by the NSO follows ESA2010 methodology. The methodological changes implied by ESA2010 could potentially have a significant impact on the supply and use system, the volume of exports and imports and underlying inter-industry linkages (Sixta et. al., 2014 and Van den Cruyce, B.,

${ }_{9}^{9}$ For the purpose of his study Cassar (2015) also derives the respective output, employment and income multipliers. A summary of the full set of multipliers relating to the tourism related sectors, including the Type I and Type II income and employment multipliers, may be found in Appendix Table 2. 
2014). This implies that the multipliers presented within NSO (2016) may, to an extent, not be strictly comparable to those derived in Cassar (2015). Furthermore, it should be acknowledged that in contrast to the study undertaken by Cassar (2015), which utilized a 59 level of sectoral disaggregation, the multipliers presented within NSO (2016) are based on a highly aggregated SIOT of 17 sectors, hence caution has to be exercised when comparing multipliers for the seemingly same industry category due to possible differences in the underlying sectoral classification.

Given the high level of aggregation presented in the input-output analysis provided by NSO (2016), it was only possible to identify two industries which may be considered to be an "integral" part of tourism, namely the transport sector and hotels and restaurants sector. It is important to note that the aggregated sector for transport incorporates all the activities which fall under the classification of land transport, sea transport, air transport, warehousing and support activities for transportation and postal and courier activities and thus may not necessarily reflect the expenditure patterns of solely tourism related activities. Table 3 illustrates the value added multipliers of the tourism related industries as presented within NSO (2016) together with the derived weighted average tourism value added multiplier ${ }^{10}$.

Table 3: A Comparison of Tourism GVA Multipliers based on NSO (2016)

\begin{tabular}{lccc}
\hline & GVA in 2010 (Million Euro) & Weight (\%) & GVA Type I Multipliers \\
Transport & 346.2 & 56.0 & 0.56 \\
Hotels and Restaurants & 272.4 & 44.0 & 0.63 \\
\hline Total & 618.6 & 100 & \\
2010 Weighted Average Tourism Multiplier & & $\mathbf{0 . 5 9}$ \\
\hline
\end{tabular}

Source: NSO (2016)

The Type I value-added multiplier for the hotels and restaurants sector of 0.63 and that of 0.56 for the Transport sector implies an increase of $€ 0.63$ and $€ 0.56$ in value added generated, respectively, per Euro increase in the final demand for each sector. In terms of their overall ranking, the hotels and restaurants sector is ranked $10^{\text {th }}$ and the transport sector is ranked $14^{\text {th }}$ which would indicate an average to low impact when evaluated within the context of a sectoral aggregation equal to 17 industries. It is interesting to note however that the Type I value added multiplier for the hotels and restaurants sector is only marginally lower than that obtained from Cassar (2015), indicating some level of stability across time. Given the classification utilized for the aggregation of the transport sector, which also includes warehousing and support activities for transportation and postal and courier activities, the value added multiplier for this sector should not be directly compared to the individual multipliers for the other transport sectors derived in Cassar (2015).

\subsection{Evaluating the contribution of tourism to the Maltese economy based on studies utilizing input-output methodology}

This section presents estimates for the contribution of tourism to the Maltese economy which are derived utilizing the multipliers obtained from the aforementioned three input-output studies. As illustrated in Table 1 as part of their study Blake et al. (2003) generated figures for the contribution of tourism, as a percentage of GDP, based on their obtained multipliers which were of $9.5 \%$ (direct contribution), $12.3 \%$ (direct and indirect), 17.1\% (direct, indirect and induced) and $29.5 \%$ (direct, indirect, induced and government interacting). As mentioned earlier the contribution of $29.5 \%$ is derived based on indirect, direct, induced and government interacting multiplier estimates which invoke some very rigid assumptions pertaining to the behaviour of the economy which could potentially lead to unrealistic and overvalued multiplier estimates.

Utilizing the weighted average tourism multipliers derived from the results obtained by Cassar (2015) and NSO (2016) the contribution of tourism to the Maltese economy in terms of value added can be estimated using the following equation (1):

$$
C_{t}=\left(\frac{W A T M_{t} X T E_{t}}{G V A_{t}}\right) \times 100
$$

Within this evaluation, the contribution of tourism to the Maltese economy $\left(C_{t}\right)$, for the given reference year of the input output table (t), is defined as the total expenditure by tourists ${ }^{11}\left(T E_{t}\right)$, for the same year, multiplied by the applied

10 The weighted average tourism multiplier is derived by multiplying each individual industry value-added multiplier to the sectors' proportional percentage share of GVA (or weighting) and aggregating across the respective two sectors.

${ }_{11}$ Figures provided by the Malta Tourism Authority. 
weighted average tourism value added multiplier (WATM $)$ and expressed as a percentage of the total GVA of the respective reference year of the input-output table.

From Table 4 it is interesting to note that notwithstanding the divergences in methodologies and time elapsed between 2001 and 2010, the results obtained from the three input-output based studies all seem to corroborate a direct and indirect contribution to the Maltese economy equal to approximately $12 \%$ of total GVA. Furthermore, observing the Type II value added multipliers, which in the case of Cassar (2015) are based on the computed Type II weighted average tourism value added multiplier, which include induced effects, we note further constancy between the two studies with a contribution of tourism at around $17 \%$ of total GVA. It is noteworthy that Oosterhaven, Peik and Stedler (1986) assert that a realistic estimate of direct and indirect effects of an increase in final demand on the economy commonly lies approximately half way between the Type I and Type II multipliers. Within the context of assessing the true contribution of tourism to the Maltese economy on the basis of the input-output studies just discussed this would imply that a realistic contribution of the tourism sector to the Maltese economy would lie in the range of 12\% to $17 \%$ of total GVA.

Table 4: Input-Output based estimates of the contribution of tourism to the Maltese Economy

\begin{tabular}{lccc}
\hline & Blake at a. (2003) & Cassar (2015) & NSO (2016) \\
(\% of GNP for 2001) & (\% of total GVA for 2008) & (\% of total GVA for 2010) \\
Direct and Indirect (Based on Type I multipliers) & 12.3 & 12.5 & 11.5 \\
Direct, indirect and induced (Based on type II multipliers) & 17.1 & 17.7 & N/A \\
\hline
\end{tabular}

Source: Blake et al. (2003), Cassar (2015), NSO (2016).

It should be noted that these results contrast significantly with those widely referenced by the Travel and Tourism Economic Impact 2015 Malta Report issued by the WTTC (2015). There is significant variance between the WTTC tourism's direct and indirect contribution of $23.8 \%$ and total contribution of $28.1 \%$ (which includes direct, indirect and induced effects) of GDP, for 2014 in comparison to what has been estimated separately by Blake et al (2003) for 2001, Cassar (2015) for 2008 and NSO (2016) for 2010. The WTTC utilizes various simplifying assumptions in its input-output analysis of the contribution of tourism which contrasts significantly with the other studies discussed in this section. As a result, a detailed assessment of the WTTC estimates is not undertaken in this analysis. It should be noted that the WTTC (2015) study did not utilize a fully specified input-output table for Malta for the derivation of the multiplier estimates, but applied technical coefficients obtained from the input-output tables of other countries where data was incomplete. It is also important to point out that there is no indication of the country source of the input-output matrices which were applied to Malta.

\section{Computable General Equilibrium Modelling of Tourism Impacts}

Computable General Equilibrium (CGE) models ${ }^{12}$ overcome several of the limitations and constraints which are inherent in input-output modelling and go beyond traditional input-output models in that they link sectors via economy-wide constraints. CGE models are economic models that use actual economic data to estimate how an economy might react to changes in policy, prices, taxes, technology or other external factors. They are an extension of input-output models, but assign a more important role to prices and elasticities, thus incorporating changing behavioural effects. It is noteworthy that the application of CGE models generally requires the use of a Social Accounting Matrix (SAM), which is an extension of the input-output table.

In the second part of the study by Blake et al. (2003) a CGE model was built around the same data of the inputoutput model, but incorporating an economic model allowing for behavioural changes in wages, prices, expenditure patterns and variable input proportions. Similar analysis but in more depth was undertaken by Sinclair et al. (2005), but a limitation of their study was the absence of a fully specified SAM.

Table 5 shows the overall effects of a 10\% increase in the 2001 tourism demand (equivalent to Lm32 million). It is clear that significant crowding out can occur from tourism expansion when proper account is taken of behavioural effects. The results indicated that in the short-run, for every Lm32 million of additional demand, only Lm18.8 million was spent in Malta, thus implying that a proportion of the stimulus from the increase in tourism demand is crowded out by higher prices. High elasticity of demand by tourists is a significant contributor to this crowding out. In the long-run, far less is

${ }^{12}$ For further reading on the application of CGE analysis towards tourism impact assessment see Dwyer, et al., (2003) and Narayan, (2004). 
crowded out primarily because there is greater labour and capital mobility between economic sectors to meet the additional demand. However, this effect is greater in the short-run due to the crowding out effect through labour constraints in the long-run, thus suggesting that the supply constraints in the labour market were deemed to hamper the industry's ability to fully meet the additional tourism demand.

Table 5: Stage 2 Report (2003) - CGE model

\begin{tabular}{|c|c|c|}
\hline Malta (2001) & Short-Run (1-2 years) & Long-Run (3-5 years or longer) \\
\hline \multicolumn{3}{|c|}{ Change in Tourism Expenditures } \\
\hline Million Lira & 18.876 & 29.158 \\
\hline$\%$ of original & 5.9 & 9.1 \\
\hline \multicolumn{3}{|l|}{ GDP } \\
\hline Million Lira & 9.443 & 7.533 \\
\hline$\%$ of original & 0.6 & 0.5 \\
\hline \multicolumn{3}{|l|}{ Multiplier } \\
\hline GDP (Million Lira) & 0.296 & 0.236 \\
\hline
\end{tabular}

Source: Blake et al. (2003)

GDP multipliers stood at 0.296 and 0.236 for the short-run and long-run, respectively, which when compared to those resulting from the input-output analysis clearly illustrate the extent to which the input-output framework can overstate the true contribution of an industry. The results obtained through the use of a CGE model incorporates numerous constraints not included in traditional input-output modelling, such as the assumption of labour and capital mobility and substitution in tourism-related industries (Frechtling and Smeral, 2010). This implies that the GDP multipliers from the CGE analysis undertaken in Blake et. al. (2003) may to an extent be viewed as more robust given that they are based on a model which better captures economic reality although one has to keep in mind the significant data limitations which constraint these results and pertaining to the lack of a fully specified SAM. Furthermore, one has to acknowledge that the actual level of labour mobility facilitated by labour migration suggests that the CGE analysis may also contain some excessive restrictions which may underestimate the multiplier effect of tourism in Malta.

\section{Conclusion and Recommendations}

The objectives of this paper were twofold. Firstly, to provide a critical overview and comparative assessment of the key studies which have been undertaken over the recent decades with the aim of empirically quantifying the impact and contribution of the tourism sector on the Maltese economy. Secondly, in attempting to identify and clarify the main discrepancies which emerge from the various studies assessed, this paper also aimed to shed further light on what could possibly be a realistic range of the impact of the tourism sector on the Maltese economy.

The construction of the first set of tourism satellite accounts for the Maltese economy by Sacco (2016) allows for an assessment which is based on the measurement of solely tourism activities. Sacco (2016) estimates the GVA generated by the tourism sector at $5.7 \%$ of the total GVA. This estimate however neglects the indirect and induced effects which are generated as a result of tourism activities. The results from input-output models estimate the direct and indirect contribution of tourism at around 12\% of GVA. Estimates by Blake et al (2003), Cassar (2015) and NSO (2016) corroborate these findings. On the basis of the Type II value added multipliers derived by Cassar (2015), the induced effects raise the potential contribution to approximately 17\% of GVA. This analysis has also shown that the WTTC estimates, which are typically quoted to justify the high contribution of tourism at approximately $30 \%$, seem to be rather excessive compared to estimates by NSO (2016), Cassar (2015) and Blake et al. (2003) even when they include the induced effects. The results obtained by both Blake et al. (2003) and by Sinclair et al. (2005), which apply CGE modelling to the Maltese economy in order to estimate the impact of tourism, suggest that the tourism multipliers derived from traditional input-output models could be overestimated given that the multipliers obtained from these studies are nearly half those obtained from traditional input-output studies. It is however important to evaluate the results obtained from the various studies discussed in this paper keeping in mind the numerous discrepancies which exist between each study in terms of statistical methodologies employed and overall data quality. 
The analysis undertaken within this paper indicates that there is a significant need for further applied research in this area given the significance of the tourism sector to the small island economy of Malta. By applying the most current input-output table for Malta to more sophisticated input-output methodologies such as in Cai et. al. (2006) could provide a better understanding of the underlying linkages of the tourism sectors with the non-tourism sectors and thus help comprehend the impact of tourism on the production structure of the Maltese economy. Also, the development and publication of an official complete TSA framework for Malta would help to better comprehend the direct impact which tourism-related activities have on the Maltese economy. Furthermore, an extension of the NSO (2016) input-output table for 2010 into a SAM would allow for the application of CGE models which would enable researchers to shed more light on the effective direct, indirect and induced contribution of the tourism sector on the Maltese economy.

\section{References}

Blake, A., Sinclair, T.M., Sugiyarto, G. and DeHann, C., (2003). The Economic Impact of Tourism in Malta. The University of Nottingham, Report for the Malta Tourism Authority.

Blake, A., Sinclair, T.M., Sugiyarto, G. and DeHann, C., (2003b). The Economic Impact of Tourism in Malta: Input-Output Modelling. The University of Nottingham, Report for the Malta Tourism Authority.

Cai, J., Leung P. and Mak J. (2006) Tourism's Forward and Backward Linkages, Journal of Travel Research, 45, pp.36-52.

Cassar, I.P., (2015). Estimates of Output, Income, Value Added and Employment Multipliers for the Maltese Economy. Published by the Central Bank of Malta, WP/03/2015.

European Commission Publication, (2014). Tourism Industry Sub-sectors Country Report, Malta. The European Commission Offices, March 2014.

Dwyer, L. et al., (2003), 'The Contribution of Tourism to a State and National Economy: A multi-regional general equilibrium analysis', Tourism Economics Vol 9 (4), pp. 431-448.

Dwyer, L. et al.., (2012). Handbook of Research Methods In Tourism. Cheltenham: Edward Elgar, 2012. Print.

Frechtling and Smeral (2010), Research paper published as Chapter 6 in Douglas G. Pearce and Richard W. Butler (2010), TOURISM RESEARCH; A 20-20 VISION, Oxford, England: Goodfellow Publishing, pp. 67-79. ISBN 978-1-906884-10-9

Hara, T., (2008), Quantitative Tourism Industry Analysis, Butterworth-Heinemann, Oxford, UK

Hara. T., (2012). Introduction to Tourism Satellite Accounts, Strategies for Tourism Industry -Micro and Macro Perspectives.Dr. Murat Kasimoglu (Ed.),InTech.

Miller, R. E. and Blair, P. D., (2009). Input-Output Analysis: Foundations and Extensions. Cambridge University Press.

Narayan, P. K. (2004), 'Economic Impact of Tourism on Fiji's Economy : Empirical Evidence from the Computable General Equilibrium Model', Tourism Economics, 10(4).

National Statistics Office of Malta (NSO), 2016. "NSO News Release 009/2016 - Cruise Passengers: Q4/2015". Published by the National Statistics Office, Lascaris, Valletta, Malta, 20 January 2016.

National Statistics Office of Malta (NSO), 2016. "NSO News Release 017/2016 - Inbound Tourists: December 2015". Published by the National Statistics Office, Lascaris, Valletta, Malta, 1 January 2016.

National Statistics Office of Malta (NSO), 2016. "NSO News Release 091/2016 - Gross Domestic Product: Q1/2016". Published by the National Statistics Office, Lascaris, Valletta, Malta, 8 June 2016.

National Statistics Office of Malta (NSO), 2016. "NSO News Release 094/2016 - Gainfully Occupied Population: December 2015". Published by the National Statistics Office, Lascaris, Valletta, Malta, 13 June 2016.

National Statistics Office of Malta (NSO), 2016. "Supply, Use and Input-Output Tables 2010". Published by the National Statistics Office, Lascaris, Valletta, Malta, 2016.

OECD, (2000). Measuring the Role of Tourism in OECD Economies. Paris: Organisation for Economic Co-operation and Development. OECD Publishing.

OECD, (2014). 'Malta', in OECD Tourism Trends and Policies 2014. OECD Publishing.

Oosterhaven, J., Piek, G. and Stedler, D., (1986). Theory and Practice of Updating Regional Versus Interregional Interindustry Tables. Papers in Regional Science, 59 (1), 57-72.

Pyatt, G. and Round, J., (1985), Social accounting matrices: A basis for planning, World Bank,Washington, D.C.

Sacco, B., (2016). Measuring the economic contribution of the tourism sector to the Maltese economy using Tourism Satellite Accounts. Unpublished Master's dissertation. University of Malta. Msida, Malta,2016.

Sinclair, T.M., Blake, A., Gooroochurn, N. and DeHann, C., (2005). Modelling Tourism Impacts on Small Island Economies: Evidence from Cyprus, Malta and Mauritius. The University of Nottingham.

Sixta J, Simonkova M, Musil P, (2014), Implementation of ESA2010/SNA2008 into Czech Input-Output Tables, paper presented as proceedings of the conference organized by the International Input-Output Association in Lisbon, July 2014.

United Nations Publication, (2010) Tourism Satellite Account: Recommended Methodological Framework 2008 (TSA: RMF 2008). Department of Economic and Social Affairs, Statistics Division, Series F No. 80/Rev.1.

Van den Cruyce, B., (2014), The impact of the new ESA rules on goods for processing on the Belgian SUT and IO tables for 2010, paper presented as proceedings of the conference organized by the International Input-Output Association in Lisbon, July 2014.

World Travel \& Tourism Council, (2015). Methodology for producing the 2015 WTTC/ Oxford Economics Travel \& Tourism Economic 
Impact Research. Published by Oxford Economics, March 2015

World Travel \& Tourism Council, (2015). Travel \& Tourism Economic Impact 2015 Malta. Published by the World Travel \& Tourism (WTTC) Offices, Harlequin Building, 65 Southwark Street, London, March 2015.

Appendix Table 1: Main Tourism Indicators

\begin{tabular}{|c|c|c|c|c|c|}
\hline & 2013 & 2014 & 2015 & $\begin{array}{l}\text { Absolute Change } \\
(2015 / 2014)\end{array}$ & $\begin{array}{l}\text { \% Change } \\
(2015 / 2014)\end{array}$ \\
\hline Total Inbound Tourists & $1,582,153$ & $1,689,809$ & $1,791,422$ & 101,612 & +6.0 \\
\hline Total Nights Spent & $12,890,268$ & $13,522,112$ & $14,217,158$ & 695,047 & +5.1 \\
\hline Average Length of Stay (nights) & 8.1 & 8.0 & 7.9 & -0.1 & -1.2 \\
\hline Cruise Passengers* & 424,566 & 465,373 & 591,682 & 126,309 & +27.1 \\
\hline Total Expenditure (€000s) & $1,440,379$ & $1,528,765$ & $1,643,945$ & 115,179 & +7.5 \\
\hline Total Expenditure per capita (€) & 910 & 905 & 918 & +13 & +1.4 \\
\hline $\begin{array}{l}\text { Average full-time employment in accommodation } \\
\text { and food services activities }{ }^{\star *}\end{array}$ & 10,103 & 10,396 & 10,686 & 290 & +2.8 \\
\hline \multicolumn{6}{|c|}{$\begin{array}{l}\text { * Excluding embarkations and Maltese cruise passengers. } \\
\text { ** The data presented is based on the distribution of the administrative records of the ETC of the gainfully occupied population } \\
\text { according to the standard NACE classification of economic activities. }\end{array}$} \\
\hline
\end{tabular}

Source: National Statistics Office, Employment and Training Corporation

Appendix Table 2: Tourism Multipliers

\begin{tabular}{|c|c|c|c|c|c|c|c|c|c|c|c|}
\hline \multirow[t]{2}{*}{ No. } & \multirow[t]{2}{*}{ Sectors } & \multicolumn{2}{|c|}{ Direct Effects } & \multicolumn{2}{|c|}{ Indirect Effects } & \multicolumn{2}{|c|}{$\begin{array}{l}\text { Type I Multiplier } \\
\text { (Direct + Indirect Effects) }\end{array}$} & \multicolumn{2}{|l|}{ Induced Effects } & \multicolumn{2}{|c|}{$\begin{array}{l}\text { Type II Multiplier } \\
\text { (Direct + Indirect + } \\
\text { Induced Effects) }\end{array}$} \\
\hline & & $\begin{array}{l}\text { Direct } \\
\text { Effects }\end{array}$ & Rank & $\begin{array}{l}\text { Indirect } \\
\text { Effects }\end{array}$ & Rank & Type I & Rank & Induced Effects & Rank & Type II & Rank \\
\hline \multicolumn{12}{|c|}{$\underline{\text { Output Multipliers }}$} \\
\hline 29 & $\begin{array}{l}\text { Land transport and } \\
\text { transport via pipelines }\end{array}$ & - & - & - & - & 1.53 & 22 & 0.45 & 45 & 1.95 & 40 \\
\hline 30 & Water transport & - & - & - & - & 1.81 & 3 & 0.44 & 43 & 2.25 & 16 \\
\hline 31 & Air transport & - & - & - & - & 1.79 & 4 & 0.61 & 21 & 2.41 & 10 \\
\hline 34 & $\begin{array}{l}\text { Accommodation and food } \\
\text { services activities }\end{array}$ & - & - & - & - & 1.63 & 12 & 0.62 & 20 & 2.25 & 15 \\
\hline \multicolumn{12}{|c|}{ Value Added Multipliers } \\
\hline 29 & $\begin{array}{l}\text { Land transport and } \\
\text { transport via pipelines }\end{array}$ & 0.47 & 27 & 0.23 & 17 & 0.69 & 27 & 0.19 & 45 & 0.88 & 31 \\
\hline 30 & Water transport & 0.17 & 54 & 0.35 & 3 & 0.52 & 45 & 0.20 & 43 & 0.71 & 49 \\
\hline 31 & Air transport & 0.11 & 56 & 0.35 & 1 & 0.46 & 54 & 0.27 & 21 & 0.74 & 45 \\
\hline 34 & $\begin{array}{l}\text { Accommodation and food } \\
\text { services activities }\end{array}$ & 0.40 & 25 & 0.25 & 11 & 0.65 & 31 & 0.28 & 20 & 0.93 & 25 \\
\hline \multicolumn{12}{|c|}{ Income Multipliers } \\
\hline 29 & $\begin{array}{l}\text { Land transport and transport } \\
\text { via pipelines }\end{array}$ & 0.14 & 46 & 0.11 & 24 & 0.25 & 45 & 0.08 & 45 & 0.33 & 45 \\
\hline 30 & Water transport & 0.10 & 52 & 0.16 & 4 & 0.26 & 43 & 0.08 & 43 & 0.34 & 43 \\
\hline 31 & Air transport & 0.19 & 31 & 0.17 & 3 & 0.36 & 21 & 0.12 & 21 & 0.48 & 21 \\
\hline 34 & $\begin{array}{l}\text { Accommodation and food } \\
\text { services activities }\end{array}$ & 0.24 & 21 & 0.12 & 14 & 0.37 & 20 & 0.12 & 20 & 0.49 & 20 \\
\hline \multicolumn{12}{|c|}{ Employment Multipliers } \\
\hline 29 & $\begin{array}{l}\text { Land transport and transport } \\
\text { via pipelines }\end{array}$ & 20 & 10 & 7 & 5 & 27 & 12 & 5 & 45 & 32 & 17 \\
\hline 30 & Water transport & 4 & 53 & 9 & 8 & 13 & 48 & 5 & 43 & 19 & 47 \\
\hline 31 & Air transport & 5 & 52 & 8 & 15 & 14 & 47 & 7 & 21 & 21 & 41 \\
\hline 34 & $\begin{array}{l}\text { Accommodation and food } \\
\text { services activities }\end{array}$ & 15 & 23 & 7 & 12 & 23 & 19 & 7 & 20 & 30 & 21 \\
\hline
\end{tabular}

Source: Estimates of output, income, value added and employment multipliers for the Maltese economy by Dr. Ian Cassar (2015) 
Appendix Table 3: Tourism Multipliers

\begin{tabular}{|c|c|c|c|c|}
\hline $2001 \quad$ Sectors & Direct & Direct + Indirect & Direct + Indirect + Induced & Direct + Indirect + Induced + Government Interacting \\
\hline \multicolumn{5}{|c|}{ P } \\
\hline$\overline{\text { Accommodation }}$ & 0.538 & 0.752 & 1.113 & 2.015 \\
\hline Restaurant & 0.487 & 0.639 & 0.900 & 1.797 \\
\hline Car Hire & 0.369 & 0.685 & 0.992 & 1.771 \\
\hline Air Malta & 0.297 & 0.412 & 0.595 & 1.119 \\
\hline Other Services & 0.413 & 0.474 & 0.683 & 1.102 \\
\hline Goods & 0.375 & 0.535 & 0.825 & 1.399 \\
\hline Total & 0.486 & 0.625 & 0.873 & 1.503 \\
\hline \multicolumn{5}{|c|}{ Employment Multipliers } \\
\hline Accommodation & 62.046 & 85.861 & 112.001 & 178.191 \\
\hline Restaurant & 62.962 & 77.927 & 96.837 & 162.692 \\
\hline Car Hire & 42.415 & 79.201 & 101.412 & 158.609 \\
\hline Air Malta & 13.809 & 48.078 & 61.330 & 99.773 \\
\hline Other Services & 46.267 & 53.517 & 68.582 & 99.357 \\
\hline Goods & 30.139 & 47.286 & 68.324 & 110.418 \\
\hline Total & 42.225 & 61.292 & 79.221 & 125.474 \\
\hline
\end{tabular}

Source: The Economic Impact of Tourism in Malta: Input-Output Modelling by Dr. Adam Blake, Professor M. Thea Sinclair and Dr. Guntur Sugiyarto (Report for the Malta Tourism Authority August 2003b) 
ISSN 2039-2117 (online)

ISSN 2039-9340 (print)
Mediterranean Journal of Social Sciences MCSER Publishing, Rome-Italy
Vol 7 No 6 November 2016 